\title{
Transcriptional regulation in response to oxygen and nitrate of the operons encoding the [NiFe] hydrogenases 1 and 2 of Escherichia coli
}

\author{
Derek J. Richard, ${ }^{1}$ Gary Sawers, ${ }^{2}$ Frank Sargent, ${ }^{3}$ Laura McWalter ${ }^{1}$ \\ and David H. Boxer ${ }^{1}$
}

1 Department of

Biochemistry, University of Dundee, Dundee DD1 4HN, Tayside, UK

2 Department of Molecular Microbiology, John Innes Centre, Norwich NR4 7UH, UK

3 Centre for Metalloprotein Spectroscopy and Biology, School of Biological Sciences, University of East Anglia, Norwich NR4 7TJ, UK

\author{
Author for correspondence: Gary Sawers. Tel: +44 1603456900 ext. 2750. Fax: +44 1603454970 \\ e-mail: gary.sawers@bbsrc.ac.uk
}

Synthesis of the [NiFe] hydrogenases 1 and 2 of Escherichia coli is induced in response to anaerobiosis and is repressed when nitrate is present in the growth medium. The hydrogenase 1 and hydrogenase 2 enzymes are encoded by the polycistronic hyaABCDEF and hybOABCDEFG operons, respectively. Primer extension analysis was used to determine the initiation site of transcription of both operons. This permitted the construction of single-copy lacZ operon fusions, which were used to examine the transcriptional regulation of the two operons. Expression of both was induced by anaerobiosis and repressed by nitrate, which is in complete accord with earlier biochemical studies. Anaerobic induction of the hyb operon was only partially dependent on the FNR protein and, surprisingly, was enhanced by an arcA mutation. This latter result indicated that ArcA suppresses anaerobic hyb expression and that a further factor, which remains to be identified, is involved in controlling anaerobic induction of operon expression. Nitrate repression of hyb expression was mediated by the NarL/NarX and NarP/NarQ two-component regulatory systems. Remarkably, a narP mutant lacked anaerobic induction of hyb expression, even in the absence of added nitrate. Anaerobic induction of hya expression was dependent on the ArcA and AppY regulators, which confirms earlier observations by other authors. Nitrate repression of the hya operon was mediated by both NarL and NarP. Taken together, these data indicate that although the hya and hyb operons share common regulators, there are important differences in the control of expression of the individual operons.

Keywords: anaerobic gene regulation, $[\mathrm{NiFe}]$ hydrogenases, Escherichia coli, nitrate regulation, transcription

\section{INTRODUCTION}

Three immunologically and genetically distinct $[\mathrm{NiFe}]$ hydrogenases, termed hydrogenase 1 , hydrogenase 2 and hydrogenase 3 , have been identified and characterized in Escherichia coli (Ballantine \& Boxer, 1985, 1986; Sawers et al., 1985; Sawers \& Boxer, 1986; Böhm et al., 1990; Menon et al., 1990, 1994; Sauter et al., 1992). More recently, the existence of a fourth enzyme has been postulated based on a genetic analysis of the E. coli chromosome (Andrews et al., 1997).

Hydrogenase 2 synthesis is induced when cells are grown anaerobically on non-fermentable carbon sources such as hydrogen and fumarate or glycerol and fumarate (Ballantine \& Boxer, 1985; Sawers et al., 1985). This led to the proposal that the function of hydrogenase 2 was in a respiratory capacity, allowing the cells to gain energy from the oxidation of molecular hydrogen. A subsequent mutational analysis of the $h y b$ structural genes encoding the enzyme confirmed this hypothesis (Menon et al., 1994).

Hydrogenase 3 forms part of the formate hydrogenlyase (FHL) complex, which, during fermentation, converts formate produced by the pyruvate formate-lyase re- 
Table 1. Bacterial strains, plasmids and phages used in this study

\begin{tabular}{|c|c|c|}
\hline $\begin{array}{l}\text { Strain, plasmid } \\
\text { or phage }\end{array}$ & Genotype & Reference or source \\
\hline \multicolumn{3}{|l|}{ Strains } \\
\hline MC4100 & $\begin{array}{l}\mathrm{F}^{-} \text {araD139 } \Delta(\arg F-l a c) U 169 \text { ptsF25 deoC1 } \\
\text { relA1 flbB350 rpsL150 } \lambda^{-}\end{array}$ & Casadaban \& Cohen (1979) \\
\hline RM102 & $\begin{array}{l}\text { Like MC4100 but } \Delta f n r \\
\Delta(\operatorname{srl}-r e c A) 306: \operatorname{Tn} 10\end{array}$ & Birkmann et al. (1987) \\
\hline RM313 & Like MC4100 but arcA1 zjj::Tn10 & Sawers \& Suppmann (1992) \\
\hline RM605 & $\begin{array}{l}\text { Like MC4100 but } \Delta \text { narX242 zch-2084:: } \Omega \\
\text { Cm narQ251::Tn10d }(\mathrm{Tc})\end{array}$ & Kaiser \& Sawers (1995) \\
\hline RM611 & $\begin{array}{l}\text { Like MC4100 but narP253::Tn10d }(\mathrm{Cm}) \\
\text { narL215:: } \operatorname{Tn} 10\end{array}$ & Kaiser \& Sawers (1995) \\
\hline $\mathrm{M} 182 \Delta c r p$ & lacX74 galK galU strA $\Delta c r p 39$ & Bell et al. (1989) \\
\hline SA2755 & $\mathrm{F}^{-}$his rpsL relA cya854 ilv:: $\operatorname{Tn} 10$ & $\begin{array}{l}\text { S. Adhya, NIH, Bethesda, MA, } \\
\text { USA }\end{array}$ \\
\hline TC3572 & $\begin{array}{l}\text { thi-1 leu-6 thr-1 lacY1 lacl-Z } \Delta(M l u) s u p E 44 \\
\text { tonA21 rpsL rfbD1 }\end{array}$ & Atlung \& Bronted (1994) \\
\hline DJR10 & Like MC4100 but $\Phi($ bya-lacZ) & This study \\
\hline DJR100 & Like MC4100 but $\Phi(b y b-l a c Z)$ & This study \\
\hline \multicolumn{3}{|l|}{ Plasmids } \\
\hline pRS551 & $\mathrm{Km}^{\mathrm{r}} \mathrm{Ap}^{\mathrm{r}} \operatorname{lacZ}^{+} \operatorname{lac}^{+} \operatorname{lacA}^{+}$ & Simons et al. (1987) \\
\hline pDCRP & Like pBR322 but $c r p^{+}$ & $\begin{array}{l}\text { S. Busby, University of } \\
\text { Birmingham, UK }\end{array}$ \\
\hline pDJR10 & Like pRS551 but containing $\Phi($ bya-lacZ $)$ & This study \\
\hline pDJR100 & Like pRS551 but containing $\Phi(b y b-l a c Z)$ & This study \\
\hline \multicolumn{3}{|l|}{ Phage } \\
\hline$\lambda \mathrm{RS} 45$ & lacZ $\operatorname{lac} \mathrm{Y}^{+}$imm21 ind $\mathrm{im}^{+}$ & Simons et al. (1987) \\
\hline
\end{tabular}

action to carbon dioxide and molecular hydrogen. Thus, the FHL complex offsets the potentially deleterious effects of formate accumulation on fermentation by maintaining $\mathrm{pH}$ homeostasis (Böhm et al., 1990; Rossmann et al., 1991; Sauter et al., 1992).

The physiological function of hydrogenase 1 is less clear. It is apparent from its subunit structure and from its overall amino acid sequence similarity with other uptake hydrogenases that it has a role in hydrogen oxidation (Menon et al., 1990). It has been proposed to be involved in recycling the hydrogen produced by hydrogenase 3 based on the fact that its synthesis shows a strong correlation with that of the FHL pathway (Sawers et al., 1985, 1986); however, such an activity for the enzyme has yet to be demonstrated unequivocally.

The results of biochemical studies indicated that synthesis of hydrogenases 1 and 2 was induced in anaerobic cultures and repressed when either nitrate or oxygen was used as terminal electron acceptor (Ballantine \& Boxer, 1985; Sawers et al., 1985). Strains unable to synthesize the global transcriptional regulator FNR (Guest et al., 1996) were also defective in the synthesis of both hydrogenase isoenzymes (Sawers et al., 1985), strongly suggesting that FNR was responsible for anaerobic induction of enzyme synthesis. However, the results of a later study (Wu et al., 1989) suggested that the reduced level of both enzymes in the fnr mutant was the consequence of impaired nickel transport. Reduced cytoplasmic nickel precludes processing of either hydrogenase precursor and, as a result, the apoenzymes were enzymically inactive and not targeted to the membrane (Rodrigue et al., 1996). An analysis of the transcriptional regulation of the operons encoding both enzymes would resolve this question unequivocally and at the same time provide key information on the control of enzyme synthesis. Such an approach has greatly enhanced our understanding of the regulation and function of hydrogenase isoenzyme 3 (Schlensog \& Böck, 1990; Lutz et al., 1990; Rossmann et al., 1991; Schlensog et al., 1994; Hopper et al., 1996).

The polycistronic operons encoding hydrogenases 1 and 2 are hyaABCDEF and hybOABCDEFG, respectively (Menon et al., 1990, 1994). Recently, Bronsted \& Atlung (1994) initiated an analysis of bya expression using a $\Phi($ bya-lacZ) gene fusion and determined that anaerobic induction is dependent on the global transcriptional regulator ArcA (Lynch \& Lin, 1996a) and a new anaerobic regulator termed AppY. They found no evidence for the involvement of FNR in transcriptional regulation of the operon. However, in these studies the details of nitrate regulation of the operon regarding the involvement of all the Nar components (Darwin \& Stewart, 1996) were not examined. No studies have been 
performed to date which analyse the transcriptional regulation of the $b y b$ operon. The recent reassignment of bybO as the first gene in the polycistronic bybOA$B C D E F G$ operon (Sargent et al., 1998) permits a detailed analysis of the transcriptional regulation of the operon encoding hydrogenase 2 . This paper describes such an analysis and identifies the factors which regulate expression of the bya and hyb operons in response to oxygen and nitrate.

\section{METHODS}

Strains and growth conditions. All strains used in this work are listed in Table 1. Strains were grown either in LB medium, or in CR-Hyd medium (Ballantine \& Boxer, 1985) at $37^{\circ} \mathrm{C}$. Carbon sources were added to the following final concentrations: glucose, $0.4 \%(\mathrm{w} / \mathrm{v})$; glycerol, $0.4 \%(\mathrm{w} / \mathrm{v})$; and ribose, $0 \cdot 4 \%(\mathrm{w} / \mathrm{v})$. Other supplements, including formate, fumarate and nitrate were added to a final concentration of $20 \mathrm{mM}$. Aerobic cultures were grown in vigourously shaken conical flasks filled to a maximum of $10 \%$ of their volume, whilst anaerobic cultures were grown either in $200 \mathrm{ml}$ or $500 \mathrm{ml}$ stoppered bottles filled to the top. Antibiotics were used at the following final concentrations: ampicillin, $50 \mathrm{mg}$ $\mathrm{l}^{-1}$; chloramphenicol, $15 \mathrm{mg} \mathrm{l}^{-1}$; and tetracycline, $15 \mathrm{mg} \mathrm{l}^{-1}$.

Plasmid construction and DNA manipulations. Recombinant DNA work was carried out according to the methods of Sambrook et al. (1989). A 526 bp DNA fragment including the hya promoter and regulatory region was amplified from the chromosome of MC4100 by PCR using Pfu DNA polymerase (Stratagene) and the oligonucleotides DTSCA-1 (5'-CCGAATTCGCGCAGAGATTCGAACTCTGG-3') and DTSCA-2 (5'-CCGCGGGATCCCTGACGCCGCATGGCC-3'). In a similar manner, the $b y b$ promoter and regulatory region was amplified as a 249 bp DNA fragment using the oligonucleotides DTSCB-1 (5'-GCGCGAATTCTATGGCCGGTTATCGCCT- ${ }^{\prime}$ ) and DTSCB-2 (5'-GCGCGGATCCGTGAGAATGGATGAGGGT- $3^{\prime}$ ). In the case of the hya DNA fragment, the promoter distal end was left blunt while the promoter proximal end was digested with BamHI. This DNA fragment was ligated into pRS551, which had been digested with EcoRI, made blunt with Klenow enzyme and subsequently digested with BamHI. This procedure delivered pRS551-Hya. The hyb promoter fragment was digested with EcoRI and BamHI and ligated into EcoRI/BamHI-digested pRS551, delivering pRS551-Hyb (Simons et al., 1987). The complete DNA sequence of each fragment was verified (Sanger et al., 1977) and the inserts were transferred to $\lambda$ RS45 (Simons et al., 1987) as previously described (Sawers \& Böck, 1989). The resulting $\Phi($ bya-lacZ) and $\Phi($ byb-lacZ) operon fusions were introduced in single copy into the $\lambda$ attachment site of wild-type strain MC4100, delivering DJR10 $\Phi($ bya-lacZ) and DJR100 $\Phi($ byb-lacZ), respectively, (Table 1). Mutations were moved into these strains by P1kc-mediated transduction (Miller, 1972).

Other methods. Total RNA was isolated from cultures grown to mid-exponential phase and primer extension analysis was carried out as described by Sawers \& Böck (1989). Analysis of the bya promoter was performed with oligonucleotide Hya-3 (5'-GTTTCCTCGTTATTCATATCGC-3') and the sequence ladder was generated using pRS551-Hya plasmid DNA. Analysis of the $h y b$ operon promoter was performed with oligonucleotide DTSCB-2 with the sequence ladder being generated using pRS551-Hyb (Sanger et al., 1977). $\beta$-Galac- tosidase enzyme activity was determined as described by Miller (1972). All assays were performed in duplicate and repeated at least three times with results varying by no more than $15 \%$.

\section{RESULTS}

\section{Identification of the hyb operon transcriptional start site}

The recent discovery of an additional gene $(b y b O)$ at the $5^{\prime}$ end of the hyb operon (Sargent et al., 1998) directs attention to the previously unexplored DNA sequence immediately upstream of bybO in order to establish the promoter and regulatory region of the operon. This was approached directly by the experimental determination of the transcriptional start site. Primer extension analysis using total RNA extracted from anaerobically grown cultures revealed a single $5^{\prime}$ end (Fig. 1a) located $102 \mathrm{bp}$

(a)

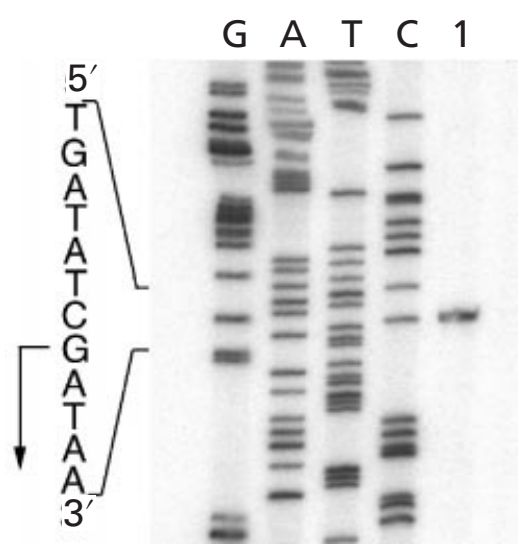

(b)

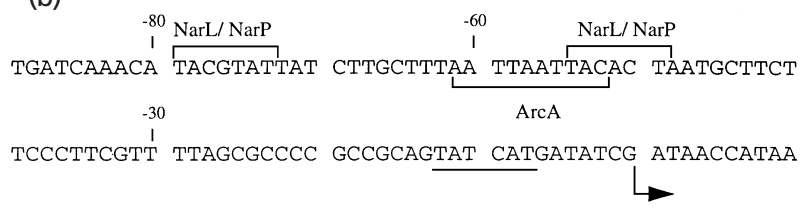

TAAATGTGTG GTAAATGGCG CATCGATCGC

NarL/ NarP

Fig. 1. Primer extension mapping of the hyb operon transcription initiation site. (a) Total RNA was isolated from MC4100 (lane 1) grown anaerobically in CR-Hyd medium with glucose as carbon source. Primer extension analysis was performed with $15 \mu \mathrm{g}$ total RNA. The location of the transcription initiation site on the DNA sequence is indicated by the bent arrow at the left of the figure. (b) The DNA sequence in the neighbourhood of the hyb operon transcription start site. The start site of transcription is located 102 bp upstream of the ATG translation initiation codon of the hybO gene (Menon et al., 1994; Sargent et al., 1998) and is indicated by the bent arrow. The putative -10 sequence upstream of the start site is underlined. Potential NarL/NarP-binding sites centred at $+20 \mathrm{bp},-51 \mathrm{bp}$ and $-76 \mathrm{bp}$ and which are similar in at least four out of seven positions relative to the consensus TACYYMT (where $\mathrm{Y}=\mathrm{C}$ or $\mathrm{T}$ and $\mathrm{M}=\mathrm{A}$ or C; Darwin et al., 1997) are indicated. A potential ArcA-binding site centred at $-56.5 \mathrm{bp}$ relative to the transcription start site and which exhibits eight out of ten matches to the consensus sequence proposed by Lynch \& Lin (1996b) is also indicated. 
Table 2. Anaerobic regulation of $\Phi($ hybO-lacZ) expression

\begin{tabular}{|lccccc|}
\hline Strain & \multicolumn{4}{c}{$\boldsymbol{\beta}$-Galactosidase specific activity (Miller units) } \\
\cline { 2 - 6 } & $\begin{array}{c}\text { Glucose }+ \\
\text { oxygen }\end{array}$ & Glucose & $\begin{array}{c}\text { Glucose }+ \\
\text { formate }\end{array}$ & $\begin{array}{c}\text { Glycerol }+ \\
\text { fumarate }\end{array}$ & $\begin{array}{c}\text { Glucose }+ \\
\text { nitrate }\end{array}$ \\
\hline MC4100 (wild-type) & 12 & 160 & 125 & 240 & 53 \\
MC4100 (fnr) & 20 & 112 & 40 & 110 & 75 \\
MC4100 (arcA) & 21 & 250 & 235 & 1115 & 60 \\
MC4100 (arcA fnr) & 11 & 47 & 54 & 135 & 45 \\
MC4100 (appY) & 12 & 115 & 155 & 230 & ND \\
\hline
\end{tabular}

ND, Not determined.

upstream from the translational start codon of the $h y b O$ gene. A putative -10 box consistent with a $\sigma^{70}$ dependent promoter was also found (Fig. 1b), which is in accord with the mapped $5^{\prime}$ end of the transcript representing the transcription initiation site of the bybO operon.

The possibility that transcription of $h y b$ may also have initiated from other sites in this region was explored in detail. No evidence was found for an additional or alternative start site following growth under aerobic or anaerobic conditions in the presence of fumarate or nitrate, or with glycerol in place of glucose as carbon source (data not shown). Analysis of cells recovered from different phases of batch growth consistently revealed the same transcriptional start site.

\section{Influence of growth conditions on hyb expression}

The newly defined transcriptional start site allowed the construction of a transcriptional reporter system. DNA extending from the translational start of $b y b O$ to $-216 \mathrm{bp}$ upstream was placed immediately upstream of a promoterless lac $Z$ gene in the plasmid pRS551 (Simons et al., 1987). This construct was incorporated into the bacteriophage lambda transducing vector $\lambda \mathrm{RS} 45$ and introduced into the chromosome of MC4100 at the $\lambda$ attachment site to form strain DJR10 (Table 1).

To explore the environmental signals which influence the regulation of $h y b$, the $\Phi(b y b-l a c Z)$ strain DJR10 carrying the chromosomal construct was grown under a variety of conditions (Table 2). We found that expression was enhanced under anaerobic fermentative conditions by approximately 13 -fold over the level for aerobic growth. Addition of formate to the growth medium did not affect the level of anaerobic expression to a significant extent. The presence of the efficient anaerobic electron acceptor nitrate, however, led to a threefold reduction in expression over the glucose fermentative level.

Respiration-dependent anaerobic growth in glycerol/fumarate medium enhanced expression just under twofold as compared to fermentative growth on glucose
(Table 2). To assess whether this elevated expression could be related to catabolite repression, cells were grown fermentatively on ribose. We observed an increase in expression of approximately $2 \cdot 5$-fold (data not shown), suggesting that $b y b$ may be subject to catabolite repression.

In summary, $h y b$ expression is anaerobically enhanced, down-regulated in the presence of nitrate and appears to be subject to catabolite repression. Each of these elements is explored further below.

\section{Anaerobic regulation of the hyb operon}

The byb operon is anaerobically regulated, with an increase in expression occurring under anaerobic conditions. Two global regulators with the potential of exerting such regulation are the FNR and ArcA proteins (Unden \& Schirawski, 1997; Lynch \& Lin, 1996a). Strains defective in each of these proteins were used to assess their possible involvement in byb regulation (Table 2). The fnr mutant strain exhibited only a slight reduction in byb expression, while the loss of ArcA function surprisingly led to an approximate $60 \%$ increase in expression. In sharp contrast to these findings, the double $\operatorname{arcA} f n r$ mutant displayed a threefold decrease in anaerobic $h y b$ expression relative to the wild-type strain when grown fermentatively with glucose. Nitrate repression in all the mutant constructs was maintained at levels seen for the wild-type. The residual anaerobic induction observed in an $\operatorname{arcA~} \mathrm{fnr}$ double mutant indicates that a further component is involved in the anaerobic induction of byb expression.

The $\operatorname{arc} A$ mutant containing the $\Phi(b y b-l a c Z)$ allele was also examined following growth on glycerol fumarate (Table 2). The anaerobic level of byb expression observed for glucose fermentative growth was enhanced a further five- to sixfold. This indicates that under these particular growth conditions ArcA acts to suppress byb expression.

The appY gene product has previously been shown to influence the expression of the bya and $c b d A B-a p p A$ operons (formerly $c p x$ ) (Bronsted \& Atlung, 1994; 
Table 3. Influence of nitrate on $\Phi($ hybO-lacZ) expression

\begin{tabular}{|lccc|}
\hline Strain & \multicolumn{3}{c|}{$\begin{array}{c}\boldsymbol{\beta} \text {-Galactosidase specific activity } \\
\text { (Miller units) }\end{array}$} \\
\cline { 2 - 4 } & $\begin{array}{c}\text { Glucose }+ \\
\text { oxygen }\end{array}$ & Glucose & $\begin{array}{c}\text { Glucose }+ \\
\text { nitrate }\end{array}$ \\
\hline MC4100 (wild-type) & 11 & 170 & 53 \\
MC4100 (narL) & 10 & 89 & 100 \\
MC4100 (narP) & 27 & 28 & 17 \\
MC4100 (narL narP) & 10 & 135 & 180 \\
\hline
\end{tabular}

Atlung et al., 1997; see below). An appY mutant containing the $\Phi(b y b-l a c Z)$ allele, however, displayed essentially unchanged $h y b$ expression under a variety of growth conditions, indicating that this putative regulator does not affect $h y b$ expression (Table 2).

\section{Nitrate regulation of the hyb operon}

Synthesis of Hyd-2 is reduced when cells are grown in the presence of nitrate (Ballantine \& Boxer, 1985; Sawers et al., 1985; Table 2). To explore the mechanism of this regulation, mutations in the genes encoding the nar transcriptional regulators NarL and NarP (Darwin \& Stewart, 1996) were moved into the $\Phi($ byb-lacZ) reporter strain. Loss of NarL led to relief of nitrate repression relative to the levels observed in glucosegrown cells (Table 3). Surprisingly, a narP mutation reduced $h y b$ expression under the anaerobic growth conditions tested, even in the absence of nitrate. The consequence of this was that in the narP mutant anaerobic induction was abolished (Table 3).

In the narL narP double null mutant, nitrate repression of $h y b$ expression was relieved and anaerobic regulation after growth in the absence of nitrate was similar to that observed in the wild-type strain (Table 3).

A narX narQ double mutant exhibited a similar phenotype with regards $h y b$ expression as did the narP
narL double mutant (data not shown). Taken together, these results indicate that nitrate regulation of the $b y b$ operon is solely accountable to the Nar regulatory system with NarL and NarP (together with NarX and NarQ) acting as redundant repressors of the $b y b$ promoter.

\section{Catabolite repression of the hyb operon}

We observed an enhanced level of $\Phi(b y b-l a c Z)$ expression during fermentation on ribose. This suggested that the $h y b$ operon is subject to catabolite repression mediated by the cAMP-CRP system (Busby \& Kolb, 1996). Expression from the $h y b$ reporter allele was tested in both crp and cya mutant strains (Table 4). The crp mutant displayed about a threefold reduction of expression anaerobically and a 16 -fold reduction aerobically. This effect was reversed by complementation with plasmid pDCRP, containing the functional crp gene. A cya mutation also resulted in lowered expression, which could be reversed by addition of cAMP to the growth medium. In the presence of both the plasmid-borne crp gene and cAMP supplementation of the growth medium, a ninefold enhancement in anaerobic $h y b$ expression was observed (data not shown). Taken together, these results indicate an involvement of cAMP-CRP in $h y b$ regulation. However, we were unable to identify by computer-assisted search a site in the $h y b$ promoter region with which the CRP protein would be expected to interact. This suggests that CRP may influence $h y b$ expression indirectly. The clear levels of control observed, however, suggests that if CRP is acting indirectly then it is probably through influencing a direct transcriptional regulator of $h y b$.

\section{Identification of the hya operon transcriptional start site}

Although a study of the transcriptional regulation of bya has been reported previously (Bronsted \& Atlung, 1994; Atlung et al., 1997), the location of the transcriptional start of the operon has not been established. Using primer extension technology, we directly determined the transcriptional start site of the operon (Fig.

Table 4. Influence of crp and cya mutations on $\Phi($ hybO-lacZ) expression

\begin{tabular}{|lcccc|}
\hline Strain & \multicolumn{3}{c|}{$\boldsymbol{\beta}$-Galactosidase specific activity (Miller units) } \\
\cline { 2 - 5 } & $\begin{array}{c}\text { Glucose }+ \\
\text { oxygen }\end{array}$ & Glucose & $\begin{array}{c}\text { Glucose }+ \\
\text { formate }\end{array}$ & $\begin{array}{c}\text { Glycerol }+ \\
\text { fumarate }\end{array}$ \\
\hline MC4100 (wild-type) & 16 & 150 & 125 & 240 \\
MC100 (crp) & 1 & 55 & 50 & 165 \\
MC4100 (crp) + pDCRP & ND & 250 & 255 & 345 \\
MC4100 (cya) & 1 & 28 & 4 & 16 \\
MC4100 (cya) +1 mM cAMP & 18 & 380 & 265 & 370 \\
\hline
\end{tabular}

ND, Not determined. 
(a)

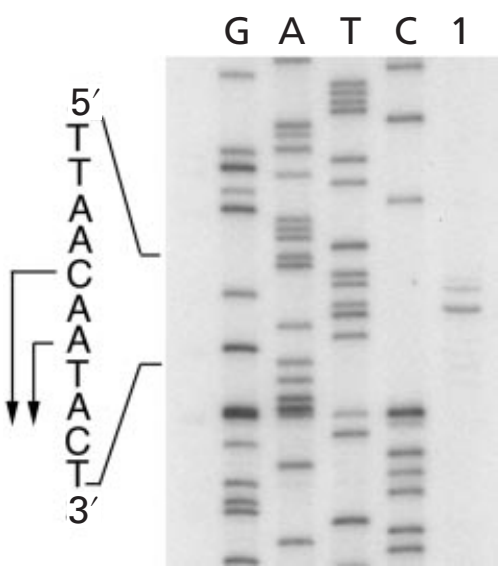

(b)

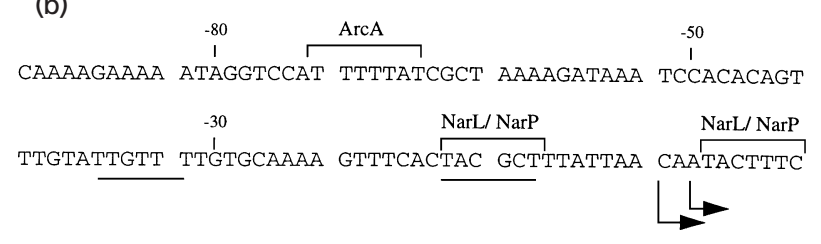

Fig. 2. Primer extension mapping of the hya operon transcription initiation sites. (a) Total RNA was isolated from MC4100 (lane 1) after anaerobic growth in CR-Hyd medium with glucose as carbon source. Primer extension analysis was performed with $15 \mu \mathrm{g}$ total RNA. The bent arrows on the left of the figure indicate the location of the mapped $5^{\prime}$ ends of the transcripts, which are located 153 and $155 \mathrm{bp}$ upstream of the ATG translation initiation codon of the hyaA gene (Menon et al., 1990). (b) A portion of the DNA sequence of the hya operon regulatory region. The bent arrows indicate the location of the mapped transcription start sites and the putative -10 and -35 RNA polymerase recognition sequences are underlined. Potential NarL/NarP-binding sites located at -12 bp and +4 bp and which match the consensus sequence of Darwin et al. (1997) in at least five out of seven positions are indicated. A potential ArcA-binding site with similarity in five out of seven positions to the consensus sequence proposed by Drapal \& Sawers (1995) is also shown. Numbering is with respect to the more $3^{\prime}$ start site, which is taken as +1 .

2a). Analysis of total RNA from anaerobically grown cultures revealed that transcription initiated from one of two bases, A or C, which are located 153 and 155 bp, respectively, upstream of the translational initiation codon of the hyaA gene. This allowed identification of putative $\sigma^{70}-10$ and -35 RNA polymerase promoter recognition sequences (Fig. 2b). No consensus sequences for alternative sigma factors could be identified upstream of the transcription start site.

The possibility that transcription may initiate from other sites upstream of hyaA could be discounted, since no other start sites were identified following growth under a variety of conditions or in different phases of growth.

\section{Influence of growth conditions on hya expression}

The distinct physiological functions that the very similar hydrogenases 1 and 2 perform in the bacterium are not clear. A comparison of the transcriptional regulation of the byb and hya operons is a useful approach to exploring the possible roles of the two enzymes. We therefore constructed a $\Phi($ byaA-lacZ) transcriptional reporter strain similar to that described above for $h y b$. A promoterless $l a c Z$ gene was fused to the DNA sequence corresponding to the region extending from $+28 \mathrm{bp}$ downstream of the translation start codon of hyaA to $-498 \mathrm{bp}$ upstream of this point (see Methods). This construct was transferred to the bacteriophage $\lambda$ RS45 transducing vector, inserted into the att $B$ site in the chromosome to form strain DJR100 (Table 1). This sequence contains some $348 \mathrm{bp}$ of regulatory sequence upstream of the transcription start site.

The switch from aerobic to anaerobic growth resulted in a 48-fold elevation in bya expression (Table 5). The presence of the terminal electron acceptor nitrate resulted in an approximate fourfold reduction in expression compared with the level in fermentatively grown cells. The addition of formate to glucose-grown cells did not affect expression significantly, whereas growth on glycerol, with fumarate as electron acceptor, gave rise to a $50 \%$ enhancement of expression compared with glucose/formate-grown cells. To assess the possibility that bya is sensitive to catabolite repression, cells were grown fermentatively on ribose. No significant difference in expression from that found for glucosegrown cells was observed (data not shown).

\section{Anaerobic regulation of the hya operon}

Anaerobic expression of hya was reduced by approximately fourfold in a f $n r$ mutant (Table 5). There is no indication of a putative FNR-binding site present at $-41.5 \mathrm{bp}$ relative to the transcription start site (Fig. $2 \mathrm{~b}$ ). These findings may indicate that the influence of FNR on bya expression is indirect.

Expression of hya was reduced approximately eightfold in a mutant lacking a functional ArcA protein (Table 5). Similar observations have been made previously (Bronsted \& Atlung, 1994). To assess whether the observed $f n r$ and $\operatorname{arc} A$ effects are linked, a double fnr arc $A$ mutant was constructed. A further reduction in bya expression was found, to give an overall 20 -fold reduction in anaerobic expression. The effects of the $f n r$ and $\operatorname{arcA}$ mutations therefore seem to be additive. Although FNR and ArcA are clearly implicated in the anaerobic regulation of hya, the level of anaerobic expression observed even in the $\operatorname{arcA} f n r$ double mutant was still greater than that found for aerobic growth (Table 5).

The reduction in bya expression in the $\operatorname{arc} A$ mutant was also substantial (4-fold) when cells were grown in glycerol/fumarate medium (Table 5). This is in marked contrast to the expression of $h y b$ in the $\operatorname{arc} A$ mutant under these conditions (see Table 2).

The appY gene has been implicated in the anaerobic regulation of bya (Bronsted \& Atlung, 1994). We confirmed their observations (Table 5) and demonstrated that in an appY mutant, anaerobic induction of bya expression was abolished, but only during fer- 
Table 5. Anaerobic regulation of $\Phi($ hyaA-lacZ) expression

\begin{tabular}{|lccccc|}
\hline Strain & \multicolumn{4}{c}{$\boldsymbol{\beta}$-Galactosidase specific activity (Miller units) } \\
\cline { 2 - 6 } & $\begin{array}{c}\text { Glucose }+ \\
\text { oxygen }\end{array}$ & Glucose & $\begin{array}{c}\text { Glucose }+ \\
\text { formate }\end{array}$ & $\begin{array}{c}\text { Glycerol }+ \\
\text { fumarate }\end{array}$ & $\begin{array}{c}\text { Glucose }+ \\
\text { nitrate }\end{array}$ \\
\hline MC4100 (wild-type) & 75 & 3650 & 4415 & 6965 & 805 \\
MC4100 (fnr) & 25 & 920 & 1220 & 545 & 910 \\
MC4100 (arcA) & 35 & 455 & 730 & 785 & 100 \\
MC4100 (arcA fnr $)$ & 50 & 175 & 230 & 390 & 95 \\
MC4100 (appY) & 60 & 75 & 330 & 360 & ND \\
\hline
\end{tabular}

ND, Not determined.

Table 6. Nitrate regulation of $\Phi($ hyaA-lacZ) expression

\begin{tabular}{|lccc|}
\hline Strain & \multicolumn{3}{c|}{$\begin{array}{c}\boldsymbol{\beta} \text {-Galactosidase specific activity } \\
\text { (Miller units) }\end{array}$} \\
\cline { 2 - 4 } & $\begin{array}{c}\text { Glucose+ } \\
\text { oxygen }\end{array}$ & Glucose & $\begin{array}{c}\text { Glucose + } \\
\text { nitrate }\end{array}$ \\
& 70 & 3940 & 810 \\
MC4100 (wild-type) & 25 & 685 & 175 \\
MC4100 (narL) & 20 & 750 & 170 \\
MC4100 (narP) & 10 & 1050 & 925 \\
MC4100 (narL narP) & 75 & 1990 & 1860 \\
MC4100 (narQ narX) & & & \\
\hline
\end{tabular}

mentative growth with glucose. Addition of formate or growth in the presence of glycerol and fumarate yielded between a five- and sixfold anaerobic induction in expression in the appY mutant (Table 5).

\section{Nitrate regulation of the hya operon}

Expression of the hya operon is reduced $4 \cdot 5$-fold when cells are grown in the presence of nitrate compared with anaerobic glucose-grown cells (Table 5). To evaluate the possible involvement of the NarL and NarP transcriptional regulators, mutations in narL and narP were moved into the reporter strain and the effects on bya expression monitored. No combination of narL and narP mutations individually restored bya expression to the levels observed for the wild-type grown anaerobically in the absence of nitrate (Table 6). Remarkably, as with byb expression, the narL and narP mutations caused a substantial reduction in bya expression after fermentative growth with glucose. Nitrate repression could however be relieved in a narL narP double mutant, indicating that both NarL and NarP mediate nitrate repression of hya expression.

In a strain defective in both nitrate-sensing proteins NarX and NarQ, nitrate repression of $\Phi($ bya-lacZ) was relieved (Table 6). These findings indicate that nitrate repression of hya expression is influenced by the NarL/NarX and NarP/NarQ nitrate-sensing systems.

\section{DISCUSSION}

This study has revealed that the expression of the bya and $h y b$ operons is regulated by both anaerobiosis and nitrate. This regulation reflects to a large extent what was observed in previous studies in which immunoelectrophoretic methods were used to study active protein levels (Ballantine \& Boxer, 1985; Sawers et al., 1985). Those early studies identified a strong dependence on FNR for hydrogenase 1 and 2 isoenzyme synthesis (Sawers et al., 1985). Later work suggested that the role of FNR was likely to be indirect and was a reflection of its requirement for nickel transport (Wu et al., 1989; Rodrigue et al., 1996). The present study demonstrated only a minor involvement of FNR in transcriptional regulation of hya (see also Bronsted \& Atlung, 1994) and hyb operon expression, which is in accord with an indirect involvement of the regulator in operon expression. Indeed, we were unable to identify an obvious FNR-binding site in either upstream regulatory region (Figs 1b, 2b), which further confirms that FNR regulates expression indirectly. It is possible that FNR exerts its effect on expression of both operons through altering the levels of intracellular nickel or a regulatory metabolite. It should be noted, however, that it still remains to be demonstrated whether nickel affects transcription of the hydrogenase gene clusters directly.

The factors regulating expression of the bya and byb operons are summarized in Fig. 3. Whilst we were able to confirm the positive roles of both AppY and ArcA in the regulation of hya (see Bronsted \& Atlung, 1994), we were also able to extend these studies by experimentally determining the start site of bya transcription. This has enabled us to define the bya operon regulatory region in more detail. We noted the presence of a potential ArcAbinding site (matching in six of eight positions) based on that proposed by Drapal \& Sawers (1995) centred at approximately $-68 \mathrm{bp}$ relative to the site of transcription initiation. DNA-binding studies with purified ArcA will be required to confirm the supposition that ArcA regulates hya expression directly.

Other than the demonstration of its involvement in the regulation of expression of the bya and $c b d A B-a p p A$ operons, little information is available concerning the 

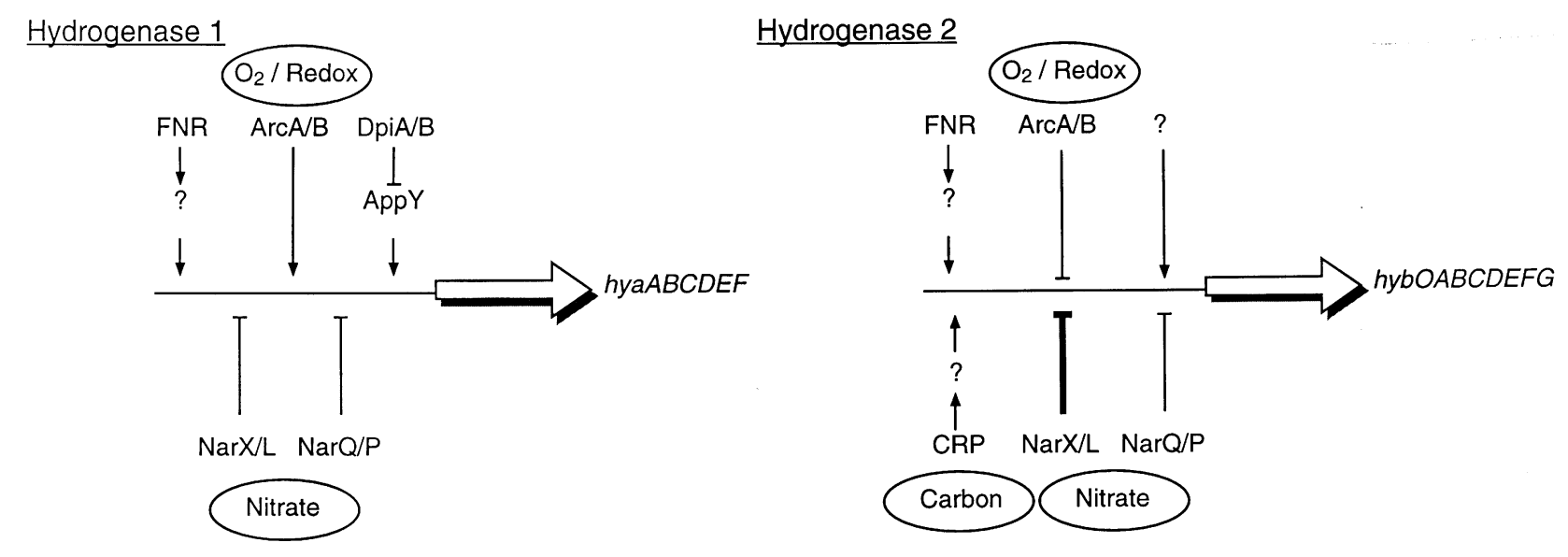

Fig. 3. Summary of the effectors involved in hya and hyb operon gene regulation. The horizontal arrows designate the hya and hyb operons. The vertical arrows indicate positive regulation, whilst the vertical lines terminated by a bar indicate negative regulation. The question mark plus arrow signifies involvement of an as yet unidentified regulator in the control of hyb expression. The question marks at CRP and FNR indicate that it is yet to be determined whether these control expression in a direct or indirect manner.

recognition sequence for AppY or its mode of action. A recent study, however, resulted in the fortuitous identification of a new two-component regulatory system, termed Dpi (destabilizer of plasmid inheritance), which controls expression of the appY gene in response to the oxygen/redox status of the cell (Ingmer et al., 1998). $\mathrm{DpiB}$ is the histidine kinase component and DpiA is proposed to be the DNA-binding response regulator. It is notable that both proteins share extensive amino acid sequence similarity with the two-component regulators of the anaerobically controlled citrate lyase operon of Klebsiella pneumoniae (Ingmer et al., 1998). Unlike the Arc system, DpiAB is functional in aerobically growing cells and the DpiA protein acts to repress appY gene expression during aerobiosis. This indicates that bya expression is controlled by two redox-responsive signal transduction systems where one is active aerobically and the other anaerobically.

In contrast to hya expression, anaerobic induction of the byb operon is not affected by $a p p Y$ mutations. As mentioned above, fnr mutations have only a minor effect on byb expression, while, surprisingly, mutations in the $\operatorname{arc} A$ gene caused an enhancement in byb expression, particularly when the cells were grown with glycerol and fumarate. This suggests a negative role for ArcA in regulation of the byb operon. Examination of the bya regulatory region failed to reveal any recognition sequence for ArcA similar to that proposed by Drapal \& Sawers (1995), but it did identify a sequence similar to that proposed by Lynch \& Lin (1996b) to be required for ArcA binding (Fig. 2b). However, this site is located at -56.5 bp with respect to the transcription start site, which would place it in an unusual location if functioning as a repressor. In $\operatorname{arcA} f n r$ double mutants a significant level ( $\sim 5$-fold) of anaerobic induction still occurs, which indicates, therefore, that another system is responsible for controlling anaerobic expression of byb.
The hyb operon is regulated by catabolite repression, which is in agreement with what was determined at the protein level for hydrogenase 2 synthesis in Salmonella typhimurium (Jamieson et al., 1986). This regulation does not appear to be related directly to the anaerobic control of operon expression. Furthermore, we were unable to identify by examination of the DNA sequence a binding site for CRP in the upstream regulatory region of the $h y b$ operon. This suggests that CRP may control expression of the operon indirectly.

Probably one of the most surprising results presented in this study is the demonstration that anaerobic induction of $h y b$ expression was abolished by a mutation in the narP gene. This was all the more remarkable since an effect of the mutation was observed even when the cells were cultivated anaerobically in the absence of added nitrate. A similar, but much less pronounced, effect was observed for the bya operon in both narL and narP mutants. This effect was specific for bya and byb expression since the same mutations do not confer the same phenotype on other genes after anaerobic growth with glucose (Kaiser \& Sawers, 1995). One possible explanation for the enhanced nitrate-dependent repression of hya gene expression in the narP mutant is that normally NarL and NarP compete to repress byb operon expression, with NarP binding being favoured. In the absence of NarP, NarL binding is unimpeded and NarL more effectively represses hya expression compared with NarP. The enhanced nitrate-dependent repression observed in a nar $X$ mutant would be in agreement with this proposal. A similar scenario exists for the E. coli napF operon, where NarL antagonizes NarP-dependent activation of expression by competing with it for the same binding site (Darwin et al., 1998). Although putative NarL heptamer recognition sequences are present in the byb operon regulatory region, these are not present in the 7-2-7 arrangement, which has been proposed by Darwin et al. (1997) to be necessary for binding of the 
NarP protein. Unless NarP, when acting as a repressor, can also recognize and occupy individual heptamer sites, as has been demonstrated for NarL, this argues against competition between the repressors as being the explanation for the enhanced repression of byb in a narP mutant background. Clearly, in vitro studies with purified NarL and NarP proteins will be required to resolve this question.

Although unlikely, a second possible explanation to account for the unusual regulation of the $h y b$ operon in a narP mutant is that the NarP protein is somehow involved in the anaerobic induction of $b y b$ expression (see Table 6). This argument would necessarily invoke the involvement of the non-phosphorylated form of NarP in this process, since without added nitrate the NarX and NarQ histidine kinases are inactive. Again, a thorough in vitro analysis will be required to test this hypothesis.

In the case of hya operon regulation, both NarL and NarP appear to be equally effective at repressing expression in the presence of nitrate (see Table 6).

This study has revealed an underlying complexity to hydrogenase 1 and 2 synthesis that was not previously anticipated. Previous immunological studies indicated that both proteins were present in the cell under roughly the same physiological conditions, making an appraisal of the function of each enzyme difficult. While it is now clear that the physiological function of hydrogenase 2 is respiratory (Menon et al., 1994), the role of hydrogenase 1 remains enigmatic. Our study has confirmed that hydrogenase 1 is more abundant than hydrogenase 2 , but it has also revealed that the bya and $b y b$ operons are regulated in response to different redox signals and by different regulators. The next stages of this work will require a detailed dissection of both regulatory regions in vivo to identify sequences necessary for both anaerobic and nitrate control and a thorough analysis in vitro using purified components to identify the locations of the binding sites of the respective regulatory proteins. By taking this dual approach, it will be possible to divulge the control mechanisms underlying hydrogenase 1 and 2 synthesis.

\section{ACKNOWLEDGEMENTS}

We thank Tove Atlung, Sankar Adhya and Steve Busby for supplying bacterial strains and Steve Busby for supplying plasmid pDCRP. This work was supported by the BBSRC (grant no. 94/CO7998 to D.H.B. and a grant-in-aid to the John Innes Centre to G.S.). D.J.R. was supported by a BBSRC studentship.

\section{REFERENCES}

Andrews, S. C., Berks, B. C., McClay, J., Ambler, A., Quail, M. A., Golby, P. \& Guest, J. R. (1997). A 12-cistron Escherichia coli operon (byf) encoding a putative proton-pumping formate hydrogenlyase system. Microbiology 143, 3633-3647.

Atlung, T. \& Bronsted, L. (1994). Role of the transcriptional activator AppY in regulation of the $c p x$ appA operon of
Escherichia coli by anaerobiosis, phosphate starvation, and growth phase. J Bacteriol 176, 5414-5422.

Atlung, T., Knudsen, K., Heerfordt, L. \& Bronsted, L. (1997). Effects of $\sigma^{\mathrm{s}}$ and the transcriptional activator AppY on induction of the Escherichia coli hya and $c b d-a p p A$ operons in response to carbon and phosphate starvation. J Bacteriol 179, 2141-2146.

Ballantine, S. P. \& Boxer, D. H. (1985). Nickel-containing hydrogenase isoenzymes from anaerobically grown Escherichia coli K12. J Bacteriol 163, 454-459.

Ballantine, S. P. \& Boxer, D. H. (1986). Isolation and characterisation of a soluble active fragment of hydrogenase isoenzyme 2 from the membranes of anaerobically grown Escherichia coli. Eur J Biochem 156, 277-284.

Bell, A. I., Gaston, K. L., Cole, J. A. \& Busby, S. W. J. (1989). Cloning of binding sequences for the Escherichia coli transcription activators, FNR and CRP: location of bases involved in discrimination between FNR and CRP. Nucleic Acids Res 17, 3865-3874.

Birkmann, A., Sawers, G. \& Böck, A. (1987). Involvement of the $n t r A$ gene product in the anaerobic metabolism of Escherichia coli. Mol Gen Genet 210, 535-542.

Böhm, R., Sauter, M. \& Böck, A. (1990). Nucleotide sequence and expression of an operon in Escherichia coli coding for formate hydrogenlyase. Mol Microbiol 4, 231-243.

Bronsted, L. \& Atlung, T. (1994). Anaerobic regulation of the hydrogenase 1 (bya) operon of Escherichia coli. J Bacteriol 176, 5423-5428.

Busby, S. \& Kolb, A. (1996). The Cap modulon. In Regulation of Gene Expression in Escherichia coli, pp. 255-279. Edited by A. S. Lynch \& E. C. C. Lin. New York: Chapman \& Hall.

Casadaban, M. J. \& Cohen, S. N. (1979). Lactose genes fused to exogenous promoters in one step using Mu-lac bacteriophage: in vivo probe for transcriptional control sequences. Proc Natl Acad Sci USA 76, 4530-4533.

Darwin, A. J. \& Stewart, V. (1996). The NAR modulon systems: nitrate and nitrite regulation of anaerobic gene expression. In Regulation of Gene Expression in Escherichia coli, pp. 343-359. Edited by A. S. Lynch \& E. C. C. Lin. New York: Chapman \& Hall.

Darwin, A. J., Tyson, K. L., Busby, S. J. W. \& Cole, J. A. (1997). Differential regulation by the homologous response regulators NarL and NarP of Escherichia coli K-12 depends on DNA binding site arrangement. Mol Microbiol 25, 583-595.

Darwin, A. J., Ziegelhoffer, E. C., Kiley, P. J. \& Stewart, V. (1998). Fnr, NarP, and NarL regulation of Escherichia coli K-12 napF (periplasmic nitrate reductase) operon transcription in vitro. $J$ Bacteriol 180, 4192-4198.

Drapal, N. \& Sawers, G. (1995). Purification of ArcA and analysis of its specific interaction with the $p f l$ promoter-regulatory region. Mol Microbiol 16, 597-607.

Guest, J. R., Green, J., Irvine, A. S. \& Spiro, S. (1996). The FNR modulon and FNR-regulated gene expression. In Regulation of Gene Expression in Escherichia coli, pp. 317-342. Edited by A. S. Lynch \& E. C. C. Lin. New York: Chapman \& Hall.

Hopper, S., Korsa, I. \& Böck, A. (1996). The nucleotide concentration determines the specificity of in vitro transcription activation by the $\sigma^{54}$-dependent activator FhlA. J Bacteriol 178, 199-203.

Ingmer, H., Miller, C. A. \& Cohen, S. N. (1998). Destabilised inheritance of pSC101 and other Escherichia coli plasmids by DpiA, a novel two-component system regulator. Mol Microbiol 29, 49-59. 
Jamieson, D. J., Sawers, R. G., Rugman, P. A., Boxer, D. H. \& Higgins, C. F. (1986). Effects of anaerobic regulatory mutations and catabolite repression on regulation of hydrogen metabolism and hydrogenase isoenzyme composition in Salmonella typhimurium. J Bacteriol 168, 405-411.

Kaiser, M. \& Sawers, G. (1995). Nitrate regulation of the Escherichia coli pfl operon is mediated by the dual sensors NarQ and NarX and the dual regulators NarL and NarP. J Bacteriol 177, 3647-3655.

Lutz, S., Böhm, R., Beier, A. \& Böck, A. (1990). Characterisation of divergent NtrA-dependent promoters in the anaerobically expressed gene cluster encoding hydrogenase 3 components of Escherichia coli. Mol Microbiol 4, 13-20.

Lynch, A. S. \& Lin, E. C. C. (1996a). Regulation of aerobic and anaerobic metabolism by the Arc system. In Regulation of Gene Expression in Escherichia coli, pp. 361-381. Edited by A. S. Lynch \& E. C. C. Lin. New York: Chapman \& Hall.

Lynch, A. S. \& Lin, E. C. C. (1996b). Transcriptional control mediated by the ArcA two-component response regulator protein of Escherichia coli: characterization of DNA binding at target sites. J Bacteriol 178, 6238-6249.

Menon, N. K., Robbins, J., Peck, H. D., Jr, Chatelus, C. Y., Choi, E.-S. \& Przybyla, A. E. (1990). Cloning and sequencing of a putative Escherichia coli $[\mathrm{NiFe}]$ hydrogenase-1 operon containing six open reading frames. J Bacteriol 172, 1969-1977.

Menon, N. K., Chatelus, C. Y., Dervartanian, M., Wendt, J. C., Shanmugam, K. T., Peck, H. D., Jr \& Przybyla, A. E. (1994). Cloning, sequencing, and mutational analyses of the hyb operon encoding Escherichia coli hydrogenase 2. J Bacteriol 176, 44164423.

Miller, J. H. (1972). Experiments in Molecular Genetics. Cold Spring Harbor, NY: Cold Spring Harbor Laboratory.

Rodrigue, A., Boxer, D. H., Mandrand-Berthelot, M. A. \& Wu, L.-F. (1996). Requirement for nickel of the transmembrane translocation of NiFe-hydrogenase 2 in Escherichia coli. FEBS Lett 392, 81-86.

Rossmann, R., Sawers, G. \& Böck, A. (1991). Mechanism of regulation of the formate-hydrogenlyase pathway by oxygen, nitrate and $\mathrm{pH}$ : definition of the formate regulon. Mol Microbiol 5, 2807-2814.

Sambrook, J., Fritsch, E. F. \& Maniatis, T. (1989). Molecular Cloning: a Laboratory Manual, 2nd edn. Cold Spring Harbor, NY: Cold Spring Harbor Laboratory.

Sanger, F., Nicklen, S. \& Coulson, A. R. (1977). DNA sequencing with chain-terminating inhibitors. Proc Natl Acad Sci USA 74, 5463-5467.
Sargent, F., Ballantine, S. P., Rugman, P. A., Palmer, T. \& Boxer, D. H. (1998). Reassignment of the gene encoding the Escherichia coli hydrogenase 2 small subunit: identification of a soluble precursor of the small subunit in a hypB mutant. Eur J Biochem $255,746-754$.

Sauter, M., Böhm, R. \& Böck, A. (1992). Mutational analysis of the operon $(b y c)$ determining hydrogenase 3 formation in Escherichia coli. Mol Microbiol 6, 1523-1532.

Sawers, G. \& Böck, A. (1989). Novel transcriptional control of the pyruvate formate-lyase gene: upstream regulatory sequences and multiple promoters regulate anaerobic expression. J Bacteriol 171, 2485-2498.

Sawers, R. G. \& Boxer, D. H. (1986). Purification and properties of membrane-bound hydrogenase isoenzyme 1 from anaerobically grown Escherichia coli. Eur J Biochem 156, 265-275.

Sawers, G. \& Suppmann, B. (1992). Anaerobic induction of pyruvate formate-lyase gene expression is mediated by the ArcA and FNR proteins. J Bacteriol 174, 3474-3478.

Sawers, R. G., Ballantine, S. P. \& Boxer, D. H. (1985). Differential expression of hydrogenase isoenzymes in Escherichia coli $\mathrm{K}-12$ : evidence for a third isoenzyme. J Bacteriol 164, 1324-1331.

Sawers, R. G., Jamieson, D. J., Higgins, C. F. \& Boxer, D. H. (1986). Characterization and physiological roles of membrane-bound hydrogenase isoenzymes from Salmonella typhimurium. J Bacteriol 168, 398-404.

Schlensog, V. \& Böck, A. (1990). Identification and sequence analysis of the gene encoding the transcriptional activator of the formate hydrogenlyase system of Escherichia coli. Mol Microbiol 4, 1319-1327.

Schlensog, V., Lutz, S. \& Böck, A. (1994). Purification and DNAbinding properties of FhlA, the transcriptional activator of the formate-hydrogenlyase system from Escherichia coli. J Biol Chem 269, 19590-19596.

Simons, R. W., Houman, F. \& Kleckner, N. (1987). Improved single and multicopy lac-based protein and operon fusion cloning tools. Gene 53, 85-96.

Unden, G. \& Schirawski, J. (1997). The oxygen-responsive transcriptional regulator FNR of Escherichia coli: the search for signals and reactions. Mol Microbiol 25, 205-210.

Wu, L.-F., Mandrand-Berthelot, M.-A., Waugh, R., Edmonds, C. J., Holt, S. E. \& Boxer, D. H. (1989). Nickel deficiency gives rise to the defective hydrogenase phenotype of hydC and fnr mutants in Escherichia coli. Mol Microbiol 3, 1709-1718.

Received 7 April 1999; revised 21 May 1999; accepted 28 May 1999. 